\title{
Effect of Collaborative Instructional Strategy on Male and Female Students' Achievement in Secondary School Chemistry in Benue State, Nigeria
}

\section{Clement Onwu Iji, Augustina Nkem Okwuchukwu Ochu, Odihi Adikwu, Sunday Esmond Atamonokhai*}

Department of Science Education, Federal University of Agriculture, Makurdi, Nigeria

\section{Email address:}

atamonokhaisunday@yahoo.com (S. E. Atamonokhai)

${ }^{*}$ Corresponding author

\section{To cite this article:}

Clement Onwu Iji, Augustina Nkem Okwuchukwu Ochu, Odihi Adikwu, Sunday Esmond Atamonokhai. Effect of Collaborative Instructional Strategy on Male and Female Students' Achievement in Secondary School Chemistry in Benue State, Nigeria. International Journal of Pharmacy and Chemistry. Vol. 3, No. 6, 2017, pp. 94-98. doi: 10.11648/j.ijpc.20170306.15

Received: October 6, 2017; Accepted: October 31, 2017; Published: November 30, 2017

\begin{abstract}
This study investigated Effect of Collaborative Instructional Strategy (CIS) on Students' Achievement in Secondary School Chemistry in Benue State, Nigeria. Its design was quasi-experimental. Its population was 6,400 Senior Secondary School two students of 301 government-approved co-educational schools in Benue State. Study sample was 216 students of 4 schools within the three Educational Zones of the state. Purposive sampling was used to select 4 out of 6 schools. Random sampling, by tossing a coin, was used to sample 2 schools for experimental group while the remaining 2 served as control group. 2 research questions and 2 hypotheses guided the study. Instrument for data collection was Chemistry Achievement Test. It was developed and validated by 3 experts; its reliability coefficient, Kuder-Richardson, K-R 21, was 0.85 . Means were used to answer research questions while ANCOVA was used to test hypotheses. Students of CIS had significantly greater mean achievement score than those of Traditional Lecture Method (TLM) and there was no significant difference in mean achievement scores due to gender of CIS. Thus, CIS was more effective in enhancing students' achievement than TLM, and was gender friendly. It was recommended that trainings be organized on use of CIS for Secondary School Chemistry teachers.
\end{abstract}

Keywords: Chemistry, Achievement, Strategy, Instruction, Collaboration, Instructional Strategy,

Collaborative Instructional Strategy

\section{Introduction}

In this 21 st century, the importance of science and technology education to national development cannot be overemphasized. This era is described as that of science and technological development in which the intelligence of the people would contribute in a great and meaningful way to the society's ability [1]. Moreover, Chemistry is deemed as the central science and the mother of all sciences [2]. Accordingly, the level of science, technology and mathematics education (STME), including chemistry, determines the level of national development [3].

\subsection{Statement of the Problem}

The present Nigerian educational system has a lot of challenges as there are consistent reports of poor performance of students in Chemistry in external examinations such as the West African Examinations Council (WAEC) and the National Examinations Council (NECO) [4]. The major contributory factor to poor performance in the sciences is the ways and means of teaching the students [5]. Furthermore, several researchers agreed that there is a high demand for a paradigm shift in the curriculum content and in the ways of teaching and learning of these subjects [6], [7], [8], [9], [10] \& [11].

Hence, a necessary paradigm shift from the conventional or traditional mode of imparting knowledge by the teacher is that of knowledge construction by the learner. This model, in which the learners construct their own understanding of concepts, is known as constructivism [12]. Constructivism is an 
instructional model that focuses on the learners' ability to construct their own understanding from their own experiences and, by so doing, making more meaning out of what they learn [13]. Collaborative instructional strategy (CIS) which is a socio-cultural approach evolved from constructivism.

CIS involves the use of small groups in which students work together to maximize and gain from one another [14]. Studies reveal several positive results in the use of collaborative instructional strategy which assist students to learn more meaningfully $[14,15]$. The findings indicate that students learn more of the materials, as their interest is kindled through motivation, team spirit and collaboration with one another. Information, which students are able to master, is usually the most likely to be retained for long and can easily be recalled and applied when the need arises [16]; such as for a great achievement in an examination.

Gender issues, which have come into prominence in the international arena and in science education, are indicated to be fostered by CIS. CIS helps to reduce gender stereotyping, as groups are usually made as heterogeneously as possible consisting of both males and females. Moreover, it is found that girls as well as boys participate actively in collaborative groups. They carry out class work, assignments, homework and projects without any form of discrimination or segregation [14]. The traditional lecture method has been shown to favor the male students more to the disadvantage of the female students owing to its competitive and individualistic nature [17]. But CIS tends to provide leverage as learners work together and help one another in their groups as siblings. This study considered gender as a subsidiary variable in order to ascertain the effect of CIS on differences in mean achievement scores of male and female students.

\subsection{Purpose of the Study}

The purpose of this study is to investigate the effect of collaborative instructional strategy on the achievement of students in Secondary School Chemistry in Benue State, Nigeria. Specifically, the study sought to:

(1) Determine the effect of collaborative instructional strategy on students' achievement in secondary school chemistry.

(2) Investigate the effect of collaborative instructional strategy on the achievements of male and female students in secondary school chemistry.

\subsection{Research Questions}

(1) What is the effect of collaborative instructional strategy on students' mean achievement score in secondary school chemistry?

(2) What is the effect of collaborative instructional strategy on the mean achievement scores of male and female students of secondary school chemistry?

\subsection{Hypotheses}

The following null hypotheses were formulated to guide the study:

(1) There is no significant difference in the mean achievement scores of secondary school students taught chemistry with the collaborative instructional strategy and those taught with the traditional lecture method.

(2) There is no significant difference in the mean achievement scores of male and female secondary school students taught chemistry with the collaborative instructional strategy.

\section{Method and Procedure}

Quasi-experimental design of non-randomized equivalent groups was used for this study. This is because the subjects who participated in the research could not be manipulated, by randomization, as in pure experimental study. The nature of the study did not allow for random assigning of subjects for treatment as the students learned in intact classes and according to their school master timetables.

This study was carried out in Benue State, Nigeria. The state is located in the north-central geo-political zone, which is part of the middle belt, of Nigeria. The entire population of the study consisted of all the 6,400 Senior Secondary School two (SSS 2) students who offered Chemistry in the 301 government approved co-educational secondary schools in Benue State in the 2015/16 academic year. The total population comprised 3,528 boys and 2,872 girls.

The sample size of the study was 216 students. It consisted of 134 males and 82 females from four schools. A multi-stage sampling method was used. Purposive sampling technique was used to choose two schools from each of the three Educational Zones A, B and $\mathrm{C}$ in the State, (making 6 schools) to participate in the pretest. Students in the six purposively sampled schools were administered the Chemistry Achievement Test (CAT) in a pretest. Then four, out of the six schools, with the closest mean scores and standard deviations, were selected for treatment and to participate in the posttest of the study. Using the random sampling method (by tossing of a coin) two of the four selected schools were made to serve as the control group while the other two served as the experimental group. All the students of these four schools (216) formed the sample for the study.

The instrument used for data collection was Chemistry Achievement Test (CAT). It comprised 50-item multiple choice objective questions constructed from Food Chemistry topics treated. Its items were derived from past Senior School Certificate Examination (SSCE) questions of both West African Examinations Council (WAEC) and National Examinations Council (NECO). Its reliability coefficient was calculated to be 0.85 using Kuder-Richardson Coefficient, K$\mathrm{R}$ 21. Descriptive statistics using mean and standard deviations were used to answer the research questions. Inferential statistics of analysis of covariance (ANCOVA) was used to test the hypotheses at $5 \%$ level of significance. 


\section{Results and Discussion}

Results of the study were organized around the research questions and their corresponding hypotheses. They are as follow:

\subsection{Research Question 1}

What is the effect of collaborative instructional strategy on students' mean achievement score in secondary school chemistry?

Table 1. Mean Achievement Scores of Students in Chemistry in the Pretest and Posttest.

\begin{tabular}{|c|c|c|c|c|c|c|}
\hline Group & $\mathbf{N}$ & Pre-Test & S.D. & Post-Test & S.D. & Mean Gain \\
\hline Collaborative Instructional Strategy (CIS) & 102 & 36.43 & 7.21 & 60.55 & 10.85 & 24.12 \\
\hline Traditional Lecture Method (TLM) & 114 & 36.79 & 8.34 & 47.42 & 9.89 & 10.63 \\
\hline $\begin{array}{l}\text { Mean Diff. } \\
\text { Total }\end{array}$ & 216 & -0.36 & & 13.13 & & 13.49 \\
\hline
\end{tabular}

$\mathrm{N}=$ Number of students; S.D. $=$ Standard deviation and Diff. $=$ Difference

Table 2. ANCOVA Table of Students' Mean Achievement Scores in Chemistry.

\begin{tabular}{|c|c|c|c|c|c|c|c|c|}
\hline Source of Variation & Df & $\mathbf{S S}_{\mathbf{X}}$ & $\mathbf{S S}_{\mathbf{Y}}$ & $\mathbf{S S}_{\mathbf{X . Y}}$ & $\mathbf{S S}_{\mathbf{Y} . \mathbf{X}}$ & $\mathbf{M S}_{\mathbf{Y} . \mathbf{X}}$ & $F_{\text {cal }}$ value & $F_{\text {tab }}$ value \\
\hline Between Groups & 1 & 6.903 & 9277.83 & -253.08 & 9767.77 & 9767.77 & 275.85 & 3.89 \\
\hline Within Groups & 214 & 13121.97 & 19807.04 & 12667.95 & 7577.40 & 35.41 & & \\
\hline Total & 215 & 13128.87 & 29084.87 & 12414.87 & 17345.17 & & & \\
\hline
\end{tabular}

NB: 1 degree of freedom was lost, from a total of 216, to give a total of 215, due to regression of Y on X.

Table 1 shows that the experimental group, which used CIS, gained more in achievement (by 24.120, in the learning of chemistry concepts, than the control group (with mean gain of 10.63) that used the TLM.

\subsection{Hypothesis 1}

There is no significant difference in the mean achievement scores of secondary school students taught chemistry with the collaborative instructional strategy and those taught with the traditional lecture method.

$\mathrm{Df}=$ Degree of freedom; $\mathrm{SS}_{\mathrm{X}}=$ Sum of squares of $\mathrm{X}$; $\mathrm{SS}_{\mathrm{Y}}=$ Sum of squares of $\mathrm{Y} ; \mathrm{SS}_{\mathrm{X} . . \mathrm{Y}}=$ Sum of products of $\mathrm{X}$ and $\mathrm{Y} ; \mathrm{SS}_{\mathrm{Y} . \mathrm{X}}=$ Adjusted sum of squares for $\mathrm{Y}$ on $\mathrm{X}$; $\mathrm{MS}_{\mathrm{Y} . \mathrm{X}}$ $=$ Mean of adjusted sum of squares for $\mathrm{Y}$ on $\mathrm{X} ; \mathrm{F}_{\mathrm{cal}}=\mathrm{F}$ calculated value and $\mathrm{F}_{\text {tab }}=\mathrm{F}$ value from table. $\mathrm{X}$ and $\mathrm{Y}$ are the interest ratings of the students in the pretest and posttest respectively. Sig. = Significant. The calculated F value (275.85) is higher than the F critical value (3.89). Hence the null hypothesis was rejected. This showed that there was a significant difference in the mean achievement scores of students taught Chemistry with the CIS and those taught with the TLM.

\subsection{Research Question 2}

What is the effect of collaborative instructional strategy on the mean achievement scores of male and female students of secondary school chemistry?

Table 3. Mean Achievement Scores of Male and Female Students of the Control (TLM) and Experimental (CIS) Groups in Chemistry.

\begin{tabular}{|c|c|c|c|c|c|c|c|}
\hline Group & Gender & $\mathbf{N}$ & Pre-Test & S.D. & Post-Test & S.D. & Mean Gain \\
\hline \multirow{2}{*}{ Collaborative Instructional Strategy (CIS) } & Male & 60 & 36.50 & 7.40 & 60.40 & 10.70 & 23.90 \\
\hline & Female & 42 & 36.33 & 7.02 & 60.76 & 11.20 & 24.43 \\
\hline Mean Diff. & & & 0.17 & & -0.36 & & -0.53 \\
\hline Total & & 102 & & & & & \\
\hline \multirow{2}{*}{ Traditional Lecture Method (TLM) } & Male & 74 & 36.81 & 8.61 & 48.03 & 8.92 & 11.22 \\
\hline & Female & 40 & 36.75 & 7.93 & 46.30 & 7.21 & 9.55 \\
\hline Total & & 114 & & & & & \\
\hline
\end{tabular}

$\mathrm{N}=$ Number of students; S.D. = Standard deviation and Diff. $=$ Difference of means

There was an indication that the collaborative instructional strategy increased the achievement scores of both male and female students in the learning of chemistry more than the traditional lecture method. Again, CIS favored the female students (with mean gain of 24.43) more than the male students (with mean gain of 23.90) while TLM favored the male students (mean gain of 11.22) more than the female students (mean gain of 9.55).

\subsection{Hypothesis 2}

There is no significant difference in the mean achievement scores of male and female secondary school chemistry students taught with the collaborative instructional strategy. 
Table 4. ANCOVA Table of Male and Female Students' Mean Achievement Scores in Chemistry of the Experimental Group (CIS).

\begin{tabular}{lllllllll}
\hline Source of Variation & Df & $\mathbf{S S}_{\mathbf{X}}$ & $\mathbf{S S}_{\mathbf{Y}}$ & $\mathbf{S S}_{\mathbf{X} \mathbf{Y}}$ & $\mathbf{S S}_{\mathbf{Y} \mathbf{X}}$ & $\mathbf{M S}_{\mathbf{Y} \mathbf{X}}$ & $\mathbf{F}_{\text {cal }}$ value & $\mathbf{F}_{\text {tab }}$ value \\
\hline Between Groups & 1 & 0.6867 & 3.231 & -1.493 & 7.681 & 7.681 & 0.165 & 3.94 \\
Within Groups & 100 & 5252.33 & 11894.02 & 6161.33 & 4666.37 & 46.664 & & \\
Total & 101 & 5253.02 & 11897.25 & 6159.84 & 4674.05 & & & \\
\hline
\end{tabular}

NB: 1 degree of freedom was lost, from a total of 102, to give a total of 101, due to regression of Y on X.

$\mathrm{Df}=$ Degree of freedom; $\mathrm{SS}_{\mathrm{X}}=$ Sum of squares of $\mathrm{X} ; \mathrm{SS}_{\mathrm{Y}}$ $=$ Sum of squares of $\mathrm{Y} ; \mathrm{SS}_{\mathrm{X} . \mathrm{Y}}=$ Sum of products of $\mathrm{X}$ and $\mathrm{Y}$; $\mathrm{SS}_{\mathrm{Y} . \mathrm{X}}=$ Adjusted sum of squares for $\mathrm{Y}$ on $\mathrm{X} ; \mathrm{MS}_{\mathrm{Y} . \mathrm{X}}=$ Mean of adjusted sum of squares for $\mathrm{Y}$ on $\mathrm{X} ; \mathrm{F}_{\mathrm{cal}}=\mathrm{F}$ calculated value and $F_{\text {tab }}=F$ value from table. $X$ and $Y$ are the interest ratings of the students in the pretest and posttest respectively. Sig. = Significant. The calculated F value $(0.165)$ is less than the F critical value (3.94). Hence the null hypothesis was not rejected. This showed that there was no significant difference in the mean achievement scores of male and female students who were taught Chemistry with the Collaborative Instructional Strategy (CIS).

\section{Discussion of Findings}

This section describes the highlights and details of the major findings of this study. The major findings are as follow:

(1) CIS increased students' achievement scores in Chemistry more than TLM;

(2) CIS was found to be more gender friendly than TLM in enhancing achievement of the students in Chemistry.

Details of the findings are as discussed below, using the research questions with their corresponding hypotheses, as a guide. They are discussed in relation to previously reviewed studies. The CIS group had higher achievement in chemistry than the group that used TLM. The calculated F value (275.85) being greater than the $F$ critical value (3.89) indicated a statistically significant difference.

The result of this study agreed with Iji [1] who asserted that the issue of poor performance in examination was due to problem of methods. He contended that there had been an increasing awareness by those concerned with mathematics education that the present methods of teaching have not been very successful in the pursuit of the objectives set for it. The study also agreed with Kolawole [8] who investigated the effects of cooperative and competitive learning on the academic performance of students in mathematics. He concluded that students taught with collaborative instructional method achieved more than those who used competitive learning strategy.

Furthermore, the study showed, generally, that CIS benefited the female students more than the male students, unlike TLM which benefited the male students more. The girls had more pretest/posttest mean gains in achievement (24.43) than the boys (23.90) with CIS. But with TLM, the boys had more pretest/posttest mean gains (11.22) than the girls (9.55). However, in spite of the more mean gain in achievement scores by the females than the males, their mean differences were not statistically significant ( $\mathrm{F}$ calculated value 0.165 as compared to $F$ table value of 3.94). In other words, CIS was more gender friendly, as it did not affect differences in their performances significantly. Thus, the study agreed with Johnson and Johnson [14]; Slavin [17] and Kolawole [8] who found that students involved in activity oriented lessons within a collaborative instructional environment usually had the girls being at par with or ahead of their male counterparts cognitively with respect to achievement and retention, while boys usually do better than the girls with the lecture method.

\section{Conclusion}

Based on the findings of this study, it can be concluded that the use of the Collaborative Instructional Strategy (CIS) significantly enhanced the achievement scores in chemistry of the students more than the Traditional Lecture Method (TLM). Also, CIS was found to be more gender friendly than TLM.

On the basis of the findings of this study, it was recommended that in-service training, in the form of workshops, seminars, symposia, conferences and long vacation courses, on the implementation of CIS, should be organized for chemistry teachers. This can be conducted periodically by school heads, professional bodies (such as the Science Teachers' Association of Nigeria (STAN), Chemical Society of Nigeria (CSN), Teachers Registration Council of Nigeria (TRCN)), institutions and Ministries of Education. Also, science teacher educators should utilize CIS in teaching would-be teachers during their training programmes. This would equip them to be able to apply this instructional strategy in their classrooms.

\section{References}

[1] CO Iji, Mathematics the language of the new millennium: Implication for mathematics teaching in Nigerian primary schools. Benue Journal of Research in Science and Education, 69 (2010), 23-30.

[2] PO Agogo and EE Otor, Basic issues in the chemistry of matter. Ibadan: Optimism Press, (2013).

[3] SE Atamonokhai, Effect of collaborative instructional strategy on students' interest, achievement and retention in chemistry in secondary schools in Benue State (Unpublished Doctoral Thesis). Federal University of Agriculture, Makurdi, (2017).

[4] OA Ogunleye, Science education in Nigeria: Historical development, curriculum reforms and research. Lagos: Sunshine International Publishers, (1999). 
[5] AR Ogunkunle and TSP Gbamanja, Constructivism: An instructional strategy for sustaining students' self-concept: In U. Nzewi (Ed.) Secondary school mathematics. Journal of Science Teachers 'Association of Nigeria, 41 (2006), 31-36.

[6] EO Odubunmi, Practical approach to the teaching and learning of genetic concepts. Science Teachers Association of Nigeria (STAN), Biology Panel Series, 1 (2005), 1-5.

[7] M Oke, An overview of some practical approaches/teaching strategies for the teaching and learning of genetic concepts: In L Ango, JO Odeyemi, AA Nwosu and LJ Etokebe (Eds.) Science teachers association of Nigeria. Biology panel series, (2005), 7-10.

[8] EB Kolawole, Effects of competitive and cooperative learning strategies on academic performance of Nigerian students in mathematics. Journal of Education Research and Review, 3 (2008), 33-41.

[9] ZC Njoku, Comparison of students' achievement in the three categories of questions in SSCE practical chemistry examination. Journal of Science Teachers' Association of Nigeria, 42 (2007), 67-72.

[10] AUG Okeke, Effective teaching of the periodic table using activity based approach: In MA Olayiwola and WS Umoh (Eds.) Science Teachers' Association of Nigeria (STAN), Chemistry Panel Series, (2007), 9-16.
[11] BA Adeyemi, Effects of cooperative learning and problem solving strategies on junior secondary school students' achievement in social studies. Electronic Journal of Research in Educational Psychology, 6 (2008), 691-708.

[12] M Epstein, Constructivism: Maureen Epstein online research portfolio, (2002). Retrieved from http://tiger.Townson.edu/mep//reserachpaper.htm

[13] KO Igboko, and OT Ibeneme, Effects of some constructivist instructional approaches on students' achievement and retention in the study of introductory technology in Nigeria, Journal of Science Teachers 'Association of Nigeria, 41(2006), 37-41.

[14] DW Johnson and RT Johnson, Cooperative learning, (2007). Retrieved from http://www.cooperation.org/pages/qanda.html

[15] T Panitz, The case for student centred instruction via collaborative learning paradigms, (2008). Retrieved from http://home.capecod.net $\sim$ tpanitz/tedarticles/coopbenefits.htm.

[16] Intelegen Inc, Memory and related learning principles, (2009). Retrieved from http://brain.webus.com/memory and related learning prin.htm.

[17] RE Slavin, When does cooperative learning increase student's achievement? (2007). Retrieved from $\mathrm{http}: / /$ www.sciencedirect/slavin_files/science.htm 